\title{
A Evasão nos Cursos de Psicologia no Brasil:Uma Revisão da Literatura
}

\author{
Carlos Alexandre Campos ${ }^{1}$ \\ ${ }^{1}$ Universidade Federal de Santa Catarina, SC, Brasil.
}

\author{
Marucia Patta Bardagi ${ }^{1}$ \\ ${ }^{1}$ Universidade Federal de Santa Catarina, SC, Brasil.
}

Resumo: A evasão no ensino superior apresenta índices significativos de ocorrência nos últimos anos. Buscar conhecer os motivos pelos quais o fenômeno ocorre pode auxiliar a compreendê-lo e pensar estratégias para a sua minimização, principalmente quando estudado o microcontexto (instituição de ensino ou curso superior específico). Este estudo realizou uma revisão da literatura sobre estudos acerca da evasão nos cursos de graduação em psicologia no Brasil, consultando-se para tanto as bases de dados SciELO, Scopus, Banco de Teses e Dissertações da Capes e Biblioteca Digital Brasileira de Teses e Dissertações, sem delimitação de período de busca. Como resultado, percebese inicialmente uma escassez de publicações, com apenas sete estudos encontrados. Quanto aos motivos da evasão, há questões que são gerais dentre as pesquisas que investigam este fenômeno em diferentes cursos superiores, como as dificuldades em conciliar trabalho e estudo, por exemplo, mas também há razões próprias do ambiente de formação em psicologia, como aspectos idealizados sobre a profissão de psicólogo, a busca do curso com finalidade terapêutica, e conflitos entre visões diferentes da psicologia - que causavam divergências. Espera-se que os dados e as considerações apresentadas auxiliem os pesquisadores e práticos que se dedicam às questões do ensino superior e, também, àqueles que se dedicam à formação de estudantes nos cursos de graduação em psicologia, uma vez que por meio do conhecimento dos principais motivos elencados por evadidos deste curso como influenciadores do abandono, pode-se planejar e implantar estratégias de prevenção ao fenômeno da evasão.

Palavras-chave: Evasão, Ensino Superior, Estudante, Psicologia.

\section{Dropouts in Brazilian Psychology Courses: A Literature Review}

\begin{abstract}
Dropout in higher education has presented significant competition rates in the last few years. Seeking to know the reasons why the phenomenon happens can help to understand and create strategies for its minimization, especially when studying its micro-context (specific higher education or course institutions). This study is a literature review about the dropout in Psychology courses in Brazil, referring to the databases SciELO, Scopus, CAPES Thesis and Dissertations Database, and Brazilian Thesis and Dissertations Digital Library, without any search period limitation. As a result, initially a lack of publications was observed, as only seven studies were found. As to the reasons for the dropout, there are general questions among the studies that investigate this phenomenon in different courses, such as the challenges of reconciling work and study, for example, but also reasons specific to the training context in Psychology, such as idealized aspects about the profession of psychologist, the pursuit of the course for therapeutic purposes, and conflicts between different views of Psychology, leading to disagreements. We hope that the data and considerations presented here will help researchers and practitioners who dedicate themselves to higher education issues, as well as those who dedicate themselves to the training of students in Psychology, since, through the knowledge of the main reasons listed for course dropouts, it is possible to plan and implement strategies of prevention to the phenomenon of dropout.
\end{abstract}

Keywords: Dropout, Higher Education, Student, Psychology. 


\title{
La Evasión en los Cursos de Psicología en Brasil: Una Revisión de la Literatura
}

\begin{abstract}
Resumen: La evasión en la enseñanza superior tiene índices significativos de ocurrencia en los últimos años. Buscar conocer los motivos por los cuales ocurre el fenómeno puede auxiliar en su comprensión y pensar estrategias para su minimización, principalmente cuando se estudia el microcontexto (institución de enseñanza o curso específico). Este estudio realizó una revisión de la literatura sobre la evasión en los cursos de graduación en Psicología en Brasil, utilizando las bases de datos SciELO, Scopus, Banco de Tesis y Disertaciones de CAPES y Biblioteca Digital Brasileña de Tesis y Disertaciones, sin delimitación de período de búsqueda. Los resultados apuntan inicialmente una escasez de publicaciones, con tan solo siete estudios encontrados. En cuanto a los motivos de la evasión, hay cuestiones que son generales entre las investigaciones que estudian este fenómeno en diferentes cursos de enseñanza superior, como las dificultades de conciliar trabajo y estudio, por ejemplo, pero también hay razones propias del ambiente de formación en Psicología, como aspectos idealizados sobre la profesión de psicólogo, la búsqueda del curso con finalidad terapéutica, y conflictos entre visiones diferentes de la Psicología, que causaban divergencias. Se espera que los datos y las consideraciones presentadas ayuden a los investigadores y prácticos que se dedican a las cuestiones de la enseñanza superior y también a aquellos que se dedican a la formación de estudiantes en los cursos de graduación en psicología, ya que por medio del conocimiento de las principales razones señaladas por evadidos de este curso como influyentes del abandono, se pueden planificar e implantar estrategias de prevención al fenómeno de la evasión.
\end{abstract}

Palabras clave: Evasión, Enseñanza Superior, Estudiante, Psicología.

\section{Introdução}

A expansão do ensino superior nos últimos anos ocorreu de modo significativo (Mancebo, Vale, \& Martins, 2015; Saviani, 2010), fato corroborado quando se analisa o número de matrículas nesse nível de ensino na última década, sendo que em 2006 houve 4.944 .877 matrículas, e em 2016 o número de matrículas chegou a 8.052.254, demonstrando crescimento elevado (Instituto Nacional de Estudos e Pesquisas Educacionais Anísio Teixeira, 2017b). Com tal crescimento, entretanto, emergem novos desafios neste cenário, analisando-se o fato de que a expansão do ensino superior se configura mais no sentido de democratização do acesso do que democratização do sucesso em relação aos estudos nesse nível de ensino (Almeida \& Soares, 2003), uma vez que maiores possibilidades de ingresso no ensino superior não garantem a permanência e o êxito do estudante para frequentar o curso superior até concluí-lo. Assim sendo, entre o ingresso na instituição de ensino superior (IES) e a colação de grau propriamente dita, há um longo trajeto a ser percorrido pelo estudante e que, por vezes, interrompe-se por meio da evasão.

Historicamente, estudos e discussões sobre a temática da evasão no ensino superior no Brasil configuravam-se como preocupação das universidades públicas e do Ministério da Educação (MEC) desde 1972, por meio da realização de estudos isolados e de pesquisas vinculadas à pós-graduação ou como parte da avaliação interna das instituições de ensino superior (Polydoro, 2000). Apesar disso, foi somente na década de 1990, mais especificamente no ano de 1995, quando foi instituída a Comissão Especial de Estudos sobre Evasão nas Universidades Públicas Brasileiras, que houve intensificação de pesquisas sobre esta temática, o que indicou valorização política sobre o fenômeno da evasão no ensino superior (Bardagi, 2007). Consistiam como objetivos da Comissão os seguintes pontos: 1) definir a evasão e aplicar uma metodologia homogeneizadora de coleta e tratamento de dados; 2) identificar índices de evasão, diplomação e retenção dos cursos de graduação; 3) apontar as causas da evasão, considerando as peculiaridades dos cursos e regiões; e 4) definir estratégias de ação voltadas à redução dos índices de evasão (Palma, 2007).

No que se refere ao termo evasão do ensino superior, Castro e Teixeira (2014) utilizam-no objetivando referir-se ao desligamento que o estudante faz do curso por qualquer outro motivo que não seja 
pela conclusão do mesmo. De acordo com a Comissão Especial de Estudos sobre Evasão (1996), há três possibilidades de evasão, a saber: evasão de curso: por meio do desligamento do estudante do seu curso de origem, sem concluí-lo, por diversas situações (abandono, desistência, transferência ou reopção, exclusão por norma institucional); evasão da instituição: quando o estudante se desliga da instituição de ensino superior em que está matriculado; e evasão do sistema: quando o estudante abandona o ensino superior. A definição apresentada, entretanto, não é compartilhada de modo unânime pelos estudiosos. Ristoff (1995), por exemplo, compartilha a definição de evasão como sendo a saída definitiva do estudante do seu curso de origem sem concluí-lo, porém utiliza também o termo mobilidade, considerando os termos como processos heterogêneos, e inferindo que este segundo termo corresponde à troca de curso, que em sua visão não se refere a um dos tipos de evasão, uma vez que em tal situação não ocorre o desligamento do estudante da IES, mas sim transferência interna. Neste estudo, optou-se por utilizar o conceito de evasão de curso - tal qual definido pela Comissão Especial de Estudos sobre Evasão (1996), e já anteriormente citado-, uma vez que o foco deste artigo é analisar as produções científicas referentes à evasão de um curso superior específico.

A evasão consiste em um fenômeno prejudicial tanto para as instituições de ensino quanto para os estudantes, mesmo que em alguns casos a mudança de curso seja positiva para o estudante (Ristoff, 1999). Quanto às instituições, os aspectos prejudiciais da evasão diferenciam-se entre as públicas e as privadas; no caso das públicas, quando um estudante abandona o curso, o dinheiro que o Estado já havia investido para a formação do mesmo constitui-se em prejuízo, sendo que a vaga poderia ter sido mais bem aproveitada, pois poderia ter sido ocupada por outro estudante que concluísse o curso e, futuramente, contribuísse com a sociedade por meio de sua qualificação profissional; já no caso das instituições privadas, se faz presente a redução da receita esperada, fator que inviabiliza diversos aspectos institucionais (Silva Filho, Motejunas, Hipólito, \& Lobo, 2007). No que se refere ao lado do estudante, evadir-se de um curso superior pode significar desperdício de tempo e dinheiro, além de consequências materiais e psicológicas (Castro \& Teixeira, 2014).

Quanto aos índices de evasão no ensino superior, por meio de um estudo no qual a taxa de evasão foi calculada com base nos estudantes desistentes em relação ao total de estudantes matriculados, constatou-se que, em 2014, a evasão média nos cursos superiores presenciais atingiu o índice de $25,4 \%$ (27,9\% nas instituições privadas e 18,3\% nas instituições públicas), e nos cursos ofertados na modalidade educação a distância (EAD) atingiu o índice de 32\% (32,5\% nas instituições privadas e $26,8 \%$ nas instituições públicas) (Sindicato das Entidades Mantenedoras de Estabelecimentos de Ensino Superior no Estado de São Paulo, 2016). Os números apresentados são expressivos quando se analisa que esta é a média geral da evasão no contexto do ensino superior brasileiro.

Referindo-se aos motivos pelos quais a evasão no ensino superior ocorre, há uma diversidade de estudos que buscou identificá-los e compreendê-los sob diferentes enfoques (perspectiva dos estudantes evadidos, dos docentes, dos coordenadores de curso, dos dirigentes universitários, entre outros), tanto no cenário brasileiro (Andriola, Andriola, \& Moura, 2006; Bardagi \& Hutz, 2009; Castro \& Teixeira, 2013; Diogo et al., 2016; Hotza, 2000; Prim \& Fávero, 2013) quanto no contexto internacional (Arce, Crespo, \& MíguezÁlvarez, 2015; Barefoot, 2004; Demetriou \& SchmitzSciborski, 2011; Heublein, 2014; Lassibille \& Gómez, 2008). Nesse sentido, diversos fatores são elencados como motivos da ocorrência da evasão discente, sendo que alguns estudos assemelham-se quanto aos resultados, mesmo quando analisado o contexto nacional com o internacional, como será explicitado na sequência, e outros apresentam diferenças.

Ao analisar os motivos referentes à evasão no ensino superior, Ribeiro (2005) apresentou que as principais pesquisas realizadas após 1985 elencaram diversos fatores como possíveis causas para a ocorrência do fenômeno. Considerando esta diversidade, destacam-se os fatores de ordem financeira, de ajustamento ao curso e/ou à universidade, educacional (como déficits nos níveis de ensino anteriores, que acarretariam dificuldades no aproveitamento acadêmico e no desenvolvimento do estudante) e, ainda, o fator da dedicação (quando o estudante necessita dedicar-se concomitantemente aos estudos e ao trabalho).

Resultados semelhantes em alguns aspectos são encontrados no estudo de Demetriou e SchmitzSciborski (2011), demonstrando que as pesquisas desenvolvidas nos Estados Unidos sobre evasão no ensino superior apontaram que a preparação acadêmica deficitária para o ingresso no ensino superior, a insatisfação com o engajamento acadêmico e social, a 
necessidade de conciliar o trabalho e o estudo, bem como características sociodemográficas (como o nível de educação dos pais, a distância de casa, ser da primeira geração a ingressar no ensino superior e o nível socioeconômico da família) são considerados os principais motivos para a evasão do ensino superior. O único aspecto que difere entre as duas pesquisas se refere às características sociodemográficas, sendo que este fator não figurou como principal no estudo de Ribeiro (2005).

De modo geral, pode-se analisar que há uma diversidade de motivos apontados em diferentes pesquisas como influenciadores da decisão do estudante em evadir-se do ensino superior. Alguns motivos são mais específicos, à medida que englobam determinado contexto (IES ou curso de graduação específicos) e outros, no entanto, aparecem recorrentemente na literatura mesmo considerando a diversidade dos contextos nos quais a evasão no ensino superior foi estudada.

Referindo-se a um contexto específico da evasão no ensino superior, o foco deste trabalho constitui-se na evasão dos cursos de graduação em psicologia. De acordo com dados do Exame Nacional de Desempenho de Estudantes (Enade) de 2015, ano mais recente no qual os cursos de graduação em psicologia foram avaliados, há no Brasil 466 cursos de graduação em psicologia, cuja maioria se situa na região sudeste (200 cursos) e sul (111 cursos) do país (Instituto Nacional de Estudos e Pesquisas Educacionais Anísio Teixeira, 2017a). O curso em questão posicionou-se na sétima colocação dentre os que contaram com maior número de matrículas no Brasil no ano de 2016, tendo totalizado 235.594 matrículas no ano em questão (Instituto Nacional de Estudos e Pesquisas Educacionais Anísio Teixeira, 2017b).

Tal dado reflete a expressiva busca por este curso. Ao mesmo tempo, este fato que desperta a necessidade de compreender sistematicamente o modo como ocorre o processo de formação dos estudantes que optam por esta carreira e, mais especificamente, os motivos que levam os estudantes a abandonar este curso superior.

Lisboa e Barbosa (2009) apontam que, desde a década de 1970, a temática da formação em psicologia tem sido objeto de inúmeros estudos e debates. As temáticas pesquisadas referem-se, comumente, à questão curricular (Medeiros, 1989; Matos, 2000;
Dias, 2001), à formação para a pesquisa (Natário, 1999; Pfromm Netto, 2007), ao estágio supervisionado (Witter \& Ferreira, 2005), às metodologias de ensino e supervisão (Bettoi \& Simão, 2002; Silva, 2004), à formação docente (Noronha, 2003), à relação entre graduação e pós-graduação (Gomes, 1996; Yamamoto, 2006), entre outras. As áreas de atuação do psicólogo também se constituem como grande foco de pesquisa, quer sejam as áreas clássicas: clínica (Ferreira Neto, 2004), escolar (Campos \& Jucá, 2010; Cruces \& Maluf, 2007; Maluf, 1994; Neves, 2007; Souza, 2007) e organizacional (Zanelli, 1994), quer sejam as consideradas áreas emergentes, como a social-comunitária (Dimenstein, 1998), jurídica (Bomfim, 1994), desportiva (Bomfim, 1994), entre outras.

Nesse contexto, entretanto, não recebem destaque as pesquisas que se dedicam a estudar a evasão dos cursos de graduação em psicologia, fato este também relacionado à formação. Se há estudantes que iniciam o curso e o concluem, há também aqueles que o iniciam e, por diversos motivos, desistem ou abandonam. Tendo em vista o exposto, consistiu como objetivo deste estudo descrever características gerais das pesquisas que investigaram a evasão nos cursos de graduação em psicologia no Brasil.

\section{Método}

Trata-se de uma revisão da literatura, com buscas realizadas durante o mês de junho do ano de 2017 nas bases de dados SciELO, Scopus, Banco de Teses e Dissertações da Capes e Biblioteca Digital Brasileira de Teses e Dissertações. Optou-se pelas bases de dados supracitadas por serem notadamente reconhecidas cientificamente, bem como por constituírem-se como bases que apresentam número significativo de pesquisas brasileiras (analisando-se que se trata de uma busca de trabalhos brasileiros); a inclusão da Scopus, mesmo sendo uma base de dados com elevados números de publicações internacionais, se deu pelo fato de apresentar um número significativo, também, de trabalhos brasileiros. Uma vez que teses e dissertações também se constituem como foco de análise, incluiu-se o Banco de Teses e Dissertações da Capes e a Biblioteca Digital Brasileira de Teses e Dissertações.

$\mathrm{Na}$ operacionalização da busca foram utilizados os seguintes descritores: de um lado, "evasão", 
"evasão universitária", "abandono", "desistência", "evadido" e, de outro lado, "psicologia", "ensino superior", "universitário", "graduando", "estudante universitário". No campo de busca utilizou-se o filtro "todos os índices/campos" e realizou-se a busca sem delimitação de período. Quanto aos tipos de publicações, analisou-se aquelas que se referiam a artigos científicos, dissertações e teses.

O número total de materiais encontrados foi de 1.803 (SciELO.org: 187; Scopus: 7; Banco de Teses e Dissertações da Capes: 1.070; Biblioteca Digital Brasileira de Teses e Dissertações: 539). Procedeu-se à leitura dos títulos e resumos, constatando-se que dentre os materiais encontrados somente 19 se referiam ao estudo da evasão em cursos de graduação em psicologia. Desconsiderando-se os trabalhos repetidos, obteve-se um total de cinco trabalhos, sendo que destes, todos corresponderam aos critérios de inclusão, a saber: ser um estudo empírico e ter sido realizado no contexto brasileiro. Por meio da indicação de materiais por especialistas na temática, constatou-se a existência de mais dois artigos científicos, os quais foram incluídos junto aos demais materiais para serem analisados. No total, então, foram analisadas sete produções sobre o tema.

A análise dos estudos foi realizada em um primeiro momento de modo individual, buscando extrair o máximo de informações de cada estudo especificamente. Analisaram-se dados gerais das pesquisas (ano, autoria, instituição, metodologia utilizada, modo como ocorreu a coleta de dados etc.), bem como se buscou analisar os resultados gerais dos estudos, considerando que se trata de um número reduzido de pesquisas com diferentes metodologias e objetivos adotados (por exemplo, estudos que também descreveram os motivos pelos quais os evadidos escolheram o curso de psicologia, e outros que detiveram-se mais especificamente aos motivos da evasão). Posteriormente, buscou-se analisar as semelhanças e diferenças apontadas pelos estudos analisados no que tange aos motivos elencados pelos sujeitos pesquisados para a evasão do curso de graduação em psicologia.

\section{Resultados}

A Tabela 1 identifica os estudos encontrados sobre o tema da evasão do curso de graduação em psicologia, seus anos de publicação, autoria, título dos trabalhos e o tipo de acesso aos mesmos. Os estudos identificados foram realizados entre os anos de 1994 e 2015. Dentre os sete trabalhos, cinco consistem em dissertações de mestrado e dois em artigos científicos. Quanto à metodologia utilizada nos estudos, três produções (Alves, 2004; Barone, 2003; Lima, Coutinho, \& Santos, 2015) utilizaram o método qualitativo e duas utilizaram métodos mistos (combinação de quantitativo e qualitativo) (Castro, 2012; Palma, 2007). Não foi possível obter esta informação quanto aos estudos de Silva (1994) e Nascimento, Guimarães, Silva e Bendassolli (1999).

Pesquisas qualitativas utilizaram, como instrumentos de coleta de dados, questionário ou entrevista. Nos estudos que utilizaram métodos mistos, análise documental, questionário, escalas e entrevistas foram os instrumentos adotados para coletar dados.

As pesquisas investigaram a evasão dos cursos de graduação em psicologia de instituições de ensino superior tanto públicas quanto privadas. Foram realizadas nos estados de São Paulo (Alves, 2004; Barone, 2003; Nascimento et al., 1999; Palma, 2007; Silva, 1994), Rio Grande do Sul (Castro, 2012) e Bahia (Lima et al., 2015).

O primeiro estudo, em termos de temporalidade, se refere à dissertação de Silva (1994). O autor identificou, entre 1980 e 1990, uma média de evadidos de $32,9 \%$ do total de estudantes que ingressaram por meio do vestibular no curso de graduação em psicologia da Universidade Estadual Paulista "Júlio de Mesquita Filho" (Unesp), campus Assis/SP. Deste percentual, quase a totalidade era constituída por estudantes do primeiro ano do curso. Neste trabalho, a evasão não foi metodologicamente caracterizada, tendo sido analisada como sinônimo de desistência ou abandono e calculada percentualmente em relação ao total de matrículas no curso. A pesquisa abordou a influência específica do curso em questão, psicologia, na decisão do abandono. A coleta de dados foi realizada com estudantes matriculados no curso de graduação em psicologia da Unesp no campus de Assis/SP, os quais apresentavam histórico e/ou intenção pregressa de abandono do curso. Os resultados obtidos evidenciaram que a frustração com a visão idealizada sobre $o$ curso, sobre a cidade e sobre a própria psicologia constitui-se como os principais fatores influenciadores da intenção de abandono do curso. 


\section{Tabela 1}

Estudos brasileiros sobre evasão nos cursos de graduação em psicologia.

\begin{tabular}{|c|c|c|c|c|}
\hline Ano & Instituição/Periódico & Autoria & Título do trabalho & Tipo de acesso \\
\hline 1994 & PUC-SP & Silva & $\begin{array}{l}\text { Entre o ideal e o real: um } \\
\text { estudo sobre as razões } \\
\text { que levam alunos de uma } \\
\text { universidade pública à } \\
\text { intenção de abandonar o curso } \\
\text { de Psicologia }\end{array}$ & $\begin{array}{l}\text { Acesso ao título e breve } \\
\text { descrição }\end{array}$ \\
\hline 1999 & $\begin{array}{l}\text { Revista Vertentes } \\
\text { (Assis) }\end{array}$ & $\begin{array}{l}\text { Nascimento, } \\
\text { Guimarães, } \\
\text { Silva, \& } \\
\text { Bendassolli }\end{array}$ & $\begin{array}{l}\text { A evasão escolar no curso } \\
\text { de graduação em Psicologia } \\
\text { da Unesp de Assis: algumas } \\
\text { considerações }\end{array}$ & Acesso ao resumo \\
\hline 2003 & $\begin{array}{l}\text { Universidade São } \\
\text { Marcos }\end{array}$ & Barone & $\begin{array}{l}\text { A formação do psicólogo na } \\
\text { cidade de São Paulo: a escolha } \\
\text { e o abandono do curso }\end{array}$ & Acesso na íntegra \\
\hline 2004 & Unisantos & Alves & $\begin{array}{l}\text { Da formação em Psicologia: } \\
\text { o problema da evasão } \\
\text { - um estudo de caso na } \\
\text { Universidade Católica de } \\
\text { Santos }\end{array}$ & Acesso na íntegra \\
\hline 2007 & FFCLRP/USP & Palma & $\begin{array}{l}\text { Experiências de evasão de um } \\
\text { curso de Psicologia }\end{array}$ & Acesso na íntegra \\
\hline 2012 & UFRGS & Castro & $\begin{array}{l}\text { Evasão no ensino superior: um } \\
\text { estudo no curso de Psicologia } \\
\text { da UFRGS }\end{array}$ & Acesso na íntegra \\
\hline 2015 & Revista CAMINE & $\begin{array}{l}\text { Lima, } \\
\text { Coutinho, \& } \\
\text { Santos }\end{array}$ & $\begin{array}{l}\text { Trajetórias interrompidas } \\
\text { no curso de Psicologia em } \\
\text { relação ao Bacharelado } \\
\text { Interdisciplinar na UFBA }\end{array}$ & Acesso na íntegra \\
\hline
\end{tabular}

A pesquisa de Nascimento et al. (1999), alguns anos depois, também foi realizada na Faculdade de Ciências e Letras da Universidade Estadual Paulista "Júlio de Mesquita Filho" (Unesp), campus Assis/SP, cujo objetivo referiu-se investigar as razões quelevam os estudantes do curso de graduação em psicologia à intenção de abandoná-lo. Os resultados evidenciaram que a decepção frente à realidade encontrada em oposição à visão romântica e idealizada do curso, aspectos relacionados à cidade de oferta do curso (Assis/SP), aspectos da psicologia enquanto ciência e profissão, problemas pessoais de adaptação, problemas relacionados à estrutura do curso e à qualidade do ensino se constituem como motivos influenciadores para a evasão. Os autores apontam, ainda, medidas visando à redução no percentual de evadidos; tais medidas se referem ao aumento de informações sobre o curso, ao oferecimento de atendimento psicológico aos estudantes, à melhoria da infraestrutura do campus, à revisão curricular do curso e à revalorização das atividades de ensino.

O estudo de Barone (2003) englobou evadidos do curso de graduação em psicologia da Universidade São Marcos no período de 1996 a 2000; a IES em questão localiza-se na cidade de São Paulo/SP. O eixo de investigação da autora foi: "que razões levam ao abandono do curso universitário escolhido, sendo que, por vezes, cursá-lo pode representar melhor qualificação e colocação no mercado de trabalho?" (Barone, 2003, p. 18). O conceito de evasão adotado no estudo se refere ao abandono do curso sem retorno ou rematrícula no mesmo curso ou em outro curso da mesma instituição.

Dentre os 86 casos de evasão constatados, somente 16 sujeitos responderam ao questionário enviado por correio. O questionário elaborado pela pesquisadora englobou cinco blocos, os quais se referiam aos seguintes aspectos: a) escolaridade; 
b) escolha pelo curso de psicologia na instituição de ensino superior em questão; c) dificuldades vivenciadas pelo estudante no decorrer do curso; d) motivos que levaram à decisão de abandonar o curso; e e) informações sobre a ocupação (anterior e atual) dos evadidos e a escolaridade de seus pais - este último bloco, especificamente, visava captar uma possível relação entre fatores socioculturais e a ocorrência da evasão. Havia, ainda, uma questão aberta, objetivando possibilitar aos sujeitos discorrer sobre aspectos que consideravam influenciadores para a evasão do curso superior.

Os resultados do estudo de Barone (2003) apontam que, quanto às características dos pesquisados, há concentração de mulheres $(84,6 \%)$ e de sujeitos com faixa etária entre 24 e 26 anos (42,3\%). A maior parcela dos pesquisados afirmou que o curso de graduação em psicologia constituiu-se como primeira opção no vestibular. Além disso, 27\% também realizou vestibular para o curso de psicologia em outras instituições. Quanto aos fatores influenciadores para a escolha do curso, elencou-se os seguintes: curiosidade sobre o curso; relacionamentos mantidos com profissionais da área, quer sejam familiares e amigos ou psicoterapeutas; recebimento de informações sobre a profissão e sobre o mercado de trabalho por meio de profissionais da área, o que facilitou a inclinação na escolha pelo curso; e expectativa de resolução de problemas pessoais. Somente quatro sujeitos relataram ter participado de processo de orientação profissional.

No que se refere ao turno no qual frequentavam o curso, $50 \%$ dos sujeitos frequentava o curso matutino e $50 \%$ frequentava o noturno; a autora considerou que, aparentemente, no conjunto estudado, tal dado não se relacionou diretamente com a decisão de evadir-se do curso. Quanto às possíveis dificuldades encontradas no decorrer do curso, os evadidos mencionaram as seguintes: dificuldade financeira; dificuldade de conciliar a vida acadêmica com compromissos familiares; dúvidas quanto à escolha do curso e futura atuação profissional; demandas externas ao ambiente universitário e que comprometiam o rendimento acadêmico; dificuldade para conciliar a vida acadêmica com compromissos no trabalho; insatisfação e decepção com o curso, comprometendo a motivação; nervosismo e ansiedade em relação às avaliações; dificuldade em produzir texto escrito e em elaborar resumo.
Referindo-se ao período no qual ocorreu a interrupção do curso, $60 \%$ dos pesquisados declarou que isso ocorreu no primeiro ano de ingresso na universidade, sendo que $42 \%$ destes abandonaram o curso ainda no primeiro semestre. Os demais sujeitos abandonaram o curso entre o terceiro e o sétimo semestre. No que concerne à pretensão de retorno aos estudos, $54 \%$ declarou não ter a intenção de retornar, $31 \%$ dos sujeitos declarou ter a intenção de retornar ao mesmo curso na mesma universidade, e o restante relatou a intenção de retorno ao curso, mas em outra instituição de ensino superior. A maior parcela (54\%), que não pretende retornar, declarou como motivos os seguintes: opção por outra área do conhecimento, descoberta de outra "vocação", e por ter desenvolvido o desinteresse pela psicologia (Barone, 2003).

Ao pensar em medidas que pudessem ser implementadas visando à redução da evasão, Barone (2003) infere que estreitar a distância entre os estudantes e a universidade pode ser considerada uma das principais ações, tendo em vista que tal ação pode propiciar a compreensão da IES sobre as necessidades e possibilidades do corpo discente e, nesse sentido, a IES tornar-se mais receptiva aos estudantes. O planejamento e a execução de programas de atendimento por parte da instituição, que não sejam unilaterais, mas que busquem promover o desenvolvimento dos estudantes, tendo em vista as transformações do mundo e as necessidades dos futuros profissionais, também é considerado pela autora como uma estratégia positiva para a permanência dos estudantes no ensino superior.

O trabalho de Alves (2004) investigou as causas da evasão do estudante que buscou a formação no curso de graduação em psicologia da Universidade Católica de Santos. A pesquisa contou com 12 participantes (oito mulheres e quatro homens), com idade entre 19 e 35 anos, cuja evasão de curso ocorreu nos anos de 2002 e 2003, e os evadidos cursaram entre o primeiro e o terceiro ano do curso. Por meio da realização de uma entrevista objetivou-se conhecer os fatores referentes à escolha, à identidade, à formação dos estudantes e às expectativas em relação à profissão de psicólogo, a fim de compreender os motivos da evasão.

Para 11 sujeitos, o curso de graduação em psicologia constituiu-se como a primeira opção no momento do vestibular. Quanto às expectativas com o curso, as mesmas se referiam à: capacitação para trabalhar nas diferentes áreas; obter maior conhecimento acerca de si; 
conhecer sobre os relacionamentos com os outros; capacitação para atuar em clínica; capacitação para atuar na área organizacional; compreender e ajudar pessoas próximas; encontrar soluções para si e para pessoas próximas. No que tange aos aspectos pessoais, somente um participante negou buscar isso no curso. Durante o período em que frequentavam o curso, todos os sujeitos residiam com as suas famílias (família de origem ou família que constituíram). No que se refere ao trabalho, no momento do ingresso no curso seis sujeitos desenvolviam atividades laborais remuneradas, e no momento da desistência esse número reduziu-se para cinco.

Os fatores elencados pelos sujeitos como influenciadores da evasão foram: fator econômico; dificuldade em acompanhar o curso; dificuldade em obter êxito nas avaliações; impossibilidade de conciliar as atividades acadêmicas com o horário de trabalho; problemas familiares; o curso não corresponder às expectativas; não identificação com o curso; desmotivação; problemas psicológicos; conceder prioridade aos filhos naquele momento. Ainda, alguns sujeitos mencionaram que o curso provocou choque de valores pessoais, familiares, morais e religiosos. Analisou-se, também, se houve apoio da família no que se refere à desistência do curso; somente um sujeito não recebeu apoio familiar, uma vez que relatou já ter cursado outros cursos superiores anteriormente e também ter desistido, então a família acreditava que dessa vez não haveria desistência. Dentre os sujeitos pesquisados, oito pretendem retornar ao curso de psicologia, podendo ou não ser na mesma universidade, e quatro não pensam em retomar o curso (Alves, 2004).

No que tange às possíveis estratégias para a redução da evasão, Alves (2004) propõe algumas. A autora considera que a conscientização do estudante sobre as possibilidades que a IES oferece, bem como o fato de propiciar a familiaridade do mesmo com o contexto do ensino superior e, mais especificamente, familiarizá-lo com o curso escolhido e com o conteúdo programático das disciplinas (de modo que perceba coerência entre as diferentes disciplinas), consistem em medidas preventivas para que o estudante sinta-se inserido e, dentro do possível, desenvolva recursos para superar as dificuldades que possam surgir.

Por meio de um estudo utilizando métodos mistos, Palma (2007) objetivou analisar a evasão no curso de graduação em psicologia da Faculdade de Filosofia, Ciências e Letras da Universidade de
São Paulo - campus Ribeirão Preto/SP (FFCLRP-USP). A primeira etapa do estudo consistiu na realização de uma análise documental, visando realizar um levantamento de índices nacionais sobre o acesso e a permanência nos cursos de graduação em psicologia. E a segunda etapa constituiu-se como um estudo de caso qualitativo sobre a evasão do curso de graduação em psicologia da instituição de ensino superior supracitada. Do total de 80 evadidos (entre 493 ingressantes) no período de 1989 a 1999, a pesquisa empírica foi realizada com oito sujeitos. A entrevista semiestruturada abrangeu questões acerca da escolaridade prévia, do grau de escolaridade e ocupação dos pais, da vivência no curso de graduação em psicologia da FFCLRP-USP nos aspectos acadêmicos e sociais, do processo de decisão pelo afastamento do curso, da avaliação do curso em seus aspectos positivos e negativos, da percepção do evadido sobre o afastamento em si, além de um posicionamento atual em relação à opção por psicologia.

No que se refere à primeira etapa da pesquisa, caracterizada pela realização de um levantamento, tornou-se possível observar uma tendência geral de aumento no número total de afastamentos nos cursos de graduação em psicologia ao longo da série histórica; dos 5.723 afastamentos em 1991, o número elevou-se para 14.666 em 2003. A análise documental possibilitou constatar, também, que a evasão ocorre predominantemente no ano de ingresso no curso (63,8\% das ocorrências) e, mais especificamente, no semestre de ingresso (50\%).

Centrando-se nas características gerais dos evadidos do curso de graduação em psicologia da FFCLRP-USP, que ingressaram entre os anos de 1989 e 1999, a maior parcela é composta por mulheres, solteiras, ingressantes com menos de 21 anos e por via do vestibular. Quanto aos sujeitos entrevistados para a pesquisa, a maioria também apresentou as mesmas características. Para todos os sujeitos é marcante o envolvimento com outros cursos de graduação, seja por vestibulares anteriores ou pela realização de outro curso superior: quatro realizaram vestibular para outra área no ano anterior à realização da pesquisa; um realizava outro curso superior; dois mostravam-se indecisos com o curso desde o vestibular. Somente um dos pesquisados, cujo afastamento não implicou na mudança de curso, realizou vestibular exclusivamente para psicologia. Ainda, há de se considerar que dois sujeitos iniciaram cursos superiores 
anteriormente ao ingresso no curso de graduação em psicologia da FFCLRP-USP: um cursou psicologia durante alguns meses em outra universidade pública, e outro realizava outro curso superior da área de ciências humanas concomitantemente ao curso de graduação em psicologia. Três entrevistados relataram ter participado de processo de orientação profissional.

No que tange às razões pelas quais escolheram o curso de graduação em psicologia e, mais especificamente, este curso na FFCLRP-USP, as respostas dos sujeitos apontaram três grandes eixos. O primeiro eixo se refere a critérios vagos ou imprecisos (dificuldade em identificar o critério; dificuldade em escolher; representação fantasiosa do curso; busca de autoconhecimento); o segundo eixo consiste na priorização pela universidade pública (especificamente pela Universidade de São Paulo - destacando-se aspectos relativos à qualidade, tradição, gratuidade do ensino e status); e o terceiro eixo, localização do curso (a preferência pela cidade de Ribeirão Preto/SP, pela possibilidade de continuar residindo junto com os pais ou o mais próximo possível dos mesmos; enquanto alternativa a residir na cidade de São Paulo/SP; pela oportunidade de acesso a uma cidade com maior diversidade cultural).

Quanto aos sentimentos em relação ao curso e à vivência acadêmica como um todo, os sujeitos descreveram experiências relativas, predominantemente, à satisfação, frustração e/ou angústia. Nos seis nos seis casos de abandono, os três estudantes que permaneceram mais tempo no curso descreveram maior insatisfação, enquanto, inversamente, três estudantes com permanência menor no curso declararam sentirem-se satisfeitos; nos dois casos restantes (desistência e transferência) não observou-se possível relação entre tempo de permanência e insatisfação com o curso.

Referindo-se aos motivos influenciadores da evasão do curso de graduação em psicologia da FFCLRP-USP, os evadidos mencionaram que a mesma ocorreu por motivos de casamento/namoro, mudança de cidade, aprovação em outro vestibular, insatisfação em relação ao curso e/ou às perspectivas profissionais e dificuldades pessoais. Enfatizaram, de modo geral, fatores de ordem individual como condicionantes da evasão. Após a evasão do curso de graduação em psicologia da FFCLRP-USP, todos os entrevistados graduaram-se em outros cursos superiores (somente um referiu estar em fase de conclusão do curso à época da realização da entrevista) (Palma, 2007).
Palma (2007) considera que o ingresso no ensino superior com poucas informações sobre as carreiras e sobre o que seja, de fato, a vida na instituição de ensino superior, são aspectos que podem elevar a probabilidade do estudante evadir. Além disso, também enfatiza o despreparo por parte da equipe dos cursos superiores em conhecer o tipo de estudante que ingressa, tendo em vista que um maior conhecimento sobre este aspecto poderia funcionar como subsídio para a organização do currículo do curso, de modo que o mesmo contribuísse, também, no sentido de informar mais sobre o curso e a profissão. Institucionalmente, ainda, a autora pontua a falta de habilidade demonstrada pela IES no manejo das situações de evasão, não promovendo diálogo eficaz com o estudante.

O estudo de Castro (2012) teve como objetivo geral descrever qualitativamente e quantitativamente o fenômeno da evasão no curso diurno de graduação em psicologia da Universidade Federal do Rio Grande do Sul (UFRGS); consiste em uma dissertação de mestrado que foi elaborada no modelo de três artigos científicos. O primeiro deles objetivou apresentar uma revisão teórica sobre os modelos internacionais de evasão e permanência e discorrer sobre instrumentos disponíveis no contexto brasileiro que abordam aspectos da vivência acadêmica, os quais podem ser utilizados em pesquisas sobre evasão.

O segundo se refere a pesquisa empírica que utilizou métodos quantitativos e constituiu-se em um levantamento, cujo objetivo consistiu em investigar aspectos associados à intenção declarada de evasão por parte dos estudantes matriculados no curso de graduação em psicologia da UFRGS no turno diurno. A coleta de dados foi realizada on-line, com 74 estudantes matriculados (do total de 280), cujas idades variavam entre 18 e 52 anos, e que estavam vinculados ao curso nos semestres 2010/2 e 2011/1.

Os instrumentos utilizados na coleta de dados foram: questionário de dados gerais e acadêmicos; quatro escalas construídas para este estudo (Compromisso com a instituição; Compromisso com a meta de graduar-se; Qualidade da escolha do curso; Percepção de oportunidades profissionais) e três escalas adaptadas (Escala de Estressores Vocacionais; Escala de Entrincheiramento de Carreira; Escala de Comprometimento com a Carreira). Como resultados, identificou-se que aspectos como o compromisso com a meta de graduar-se, o estresse total percebido, 
a baixa percepção de oportunidades profissionais, a baixa qualidade na escolha do curso, além de outros fatores, podem ser considerados como aspectos associados à probabilidade declarada de evasão.

$\mathrm{O}$ terceiro estudo refere-se a um estudo de caso coletivo, qualitativo e exploratório, cujos resultados consistiram em uma posterior publicação científica (Castro \& Teixeira, 2013). Para a coleta de dados realizou-se entrevistas semiestruturadas que abrangeram três temáticas, a saber: primeira escolha; vivência acadêmica; evasão, situação atual e possíveis intervenções. Os sujeitos pesquisados foram seis evadidos (do total de 32 casos de evasão entre os ingressantes entre 2004 e 2009), sendo três ingressantes até 2006 e três ingressantes após 2007, quando houve mudança de currículo do curso. A idade dos entrevistados se situava entre 19 e 26 anos, e os mesmos cursaram entre dois e cinco semestres do curso de graduação em psicologia diurno da UFRGS. Os resultados indicaram que tanto fatores relacionados a questões pessoais quanto fatores relacionados a questões institucionais são influenciadores da decisão de evadir. Sobre as questões pessoais, destacam-se os seguintes aspectos: baixa motivação para realização das tarefas do curso; dificuldades de relacionamentos com colegas/sensação de não pertencimento; e percepção de incongruência entre autoconceito vocacional e características da profissão, associada a baixo comportamento exploratório antes e após o ingresso no curso. Quanto às questões institucionais, destacam-se: relacionamento frio/distante com professores; focalização do currículo em algumas áreas específicas; e conflitos entre visões diferentes da psicologia, levando a divergências entre os departamentos (e mesmo entre os estudantes) (Castro, 2012).

$\mathrm{O}$ autor pontuou o fato de que a organização curricular com vieses introduzidos no currículo pelas visões da psicologia predominantes em cada IES devem ser evitados, pois este fator pode limitar o desenvolvimento do estudante e, desse modo, contribuir para a evasão. Questões gerais sobre o desenvolvimento de carreira, que podem e devem ser abordadas pelas IES, são consideradas por Castro (2012) como indispensáveis de que sejam realizadas também durante a educação básica, o que possibilitaria maior comportamento exploratório e tenderia a reduzir os índices de evasão dos cursos superiores. No tangente mais diretamente à instituição de ensino superior, esta poderia orientar os docentes sobre a forma de lidar com os estudantes, propiciando a integração entre professor-estudante, além de realizar possíveis atualizações e adaptações no currículo do curso, privilegiando do melhor modo possível as diferentes áreas da psicologia, e possibilitar maior integração entre os departamentos do curso, fomentando o respeito entre profissionais com diferentes visões sobre a ciência psicológica.

A pesquisa mais recente encontrada referente à temática da evasão no curso de graduação em psicologia foi a realizada por Lima et al. (2015), na Universidade Federal da Bahia (UFBA), que abordou a evasão do curso de graduação em psicologia, sendo este uma continuidade do bacharelado interdisciplinar, de modo que o estudante inicia o bacharelado interdisciplinar e, na sequência, passa ao curso de progressão linear, que é, nesse caso, o curso de graduação em psicologia. Neste estudo, a evasão é compreendida como a "trajetória interrompida dos estudantes". Os sujeitos pesquisados foram seis (do total de 10) estudantes que ingressaram nos anos de 2009 e 2012 e abandonaram o curso. Quanto ao perfil dos pesquisados, quatro são mulheres e dois são homens, solteiros, cujas idades variaram entre 21 e 31 anos. A coleta de dados realizou-se por meio de entrevistas (realizadas por telefone ou por e-mail).

No que se refere ao processo de escolha pelo curso de graduação em psicologia, três sujeitos tinham este curso como primeira opção. Os principais motivos relatados para a escolha do curso remetem-se à expectativa de adquirir, com a profissão, maior conhecimento sobre o outro e/ou sobre si mesmo, bem como a curiosidade sobre o funcionamento do ser humano. Quanto à expectativa frente ao ingresso no curso, três evadidos relataram que não tiveram suas expectativas correspondidas e três afirmaram que as expectativas foram correspondidas. No que tange à adaptação ao curso, os sujeitos relataram algumas dificuldades envolvidas no processo de inserção e permanência, como a falta de atividades práticas e o fato do curso ser ofertado no turno matutino - o que impossibilita o estudante de trabalhar; em relação à universidade, os sujeitos mencionaram que a infraestrutura do campus é uma dificuldade.

Como resultados referentes aos motivos da evasão, obteve-se que a falta de informações sobre o curso, as dificuldades para conciliar os horários, a precocidade na escolha do curso, os problemas de ordem pessoal e a realização de outros projetos foram os fatores influenciadores para a evasão 
dos sujeitos pesquisados. Discorre-se, ainda, sobre o fato de todos os sujeitos não terem vivenciado o processo de evasão como traumático ou aversivo, apesar de que nenhum deles solicitou formalmente a desistência do curso, aspecto este apontado pelas autoras como necessário de reflexão acerca da imagem social que o estudante tem da instituição de ensino superior pública (Lima et al., 2015).

Detendo-se às possíveis estratégias das IES para a redução da evasão, Lima et al. (2015) pontuam que, em primeiro lugar, não se deve culpabilizar o estudante pela evasão. As autoras refletem sobre a escolha profissional ser orientada em uma perspectiva institucional, não constituindo-se como responsabilidade pessoal do estudante e prévia à sua inserção no ensino superior, considerando, deste modo, que uma escolha profissional bem orientada pode reduzir significativamente a evasão.

\section{Discussão}

Inicialmente, tornou-se possível verificar a escassez de pesquisas que enfocam a temática analisada, tal como já apontado por Palma (2007) há uma década; desde então, surgiram somente dois novos estudos com foco na evasão dos cursos de graduação em psicologia. Outro dado que desperta atenção é a concentração dos estudos no estado de São Paulo, e a existência de somente outros dois estudos fora deste estado: um no Rio Grande do Sul e um na Bahia, como mencionado na seção anterior. Torna-se relevante que se busque compreender os motivos da evasão dos cursos de graduação em psicologia que são ofertados em outras regiões geográficas também, haja vista as peculiaridades de cada região em um país multicultural como o Brasil.

No que se refere ao embasamento teórico dos estudos analisados, somente a pesquisa de Castro (2012) utilizou uma teoria específica de evasão para a análise dos dados, sendo esta a teoria desenvolvida por Robbins et al. (2004). Esse dado corrobora a afirmação de Castro e Teixeira (2014) acerca de que, geralmente, não há aprofundamento teórico sobre a evasão em si nos estudos que investigam o fenômeno; em parte, isso pode ser explicado pelo fato de não haver um modelo de evasão que tenha sido desenvolvido no contexto brasileiro. Ainda assim, seria importante que os autores preocupados com esta temática e que desenvolvem estudos acerca da evasão conheçam e, principalmente, respaldem seus estudos com as contribuições teóricas existentes.
De acordo com os estudos analisados, os principais motivos para a escolha do curso de graduação em psicologia são: curiosidade sobre o curso e seus temas; expectativa de obter maior autoconhecimento e de resolução de problemas pessoais; expectativa de capacitação para atuar em diferentes áreas; desejo de conhecer sobre os relacionamentos com os outros; busca por compreender e ajudar pessoas próximas. Resultados de estudos brasileiros (Bueno, Lemos, \& Tomé, 2004; Gondim, Magalhães, \& Bastos, 2010; Krawulski \& Patrício, 2005; Lins, Silva, \& Assis, 2015; Mello, 1983) que investigaram os motivos da escolha pelo curso de graduação em psicologia não se diferenciam dos motivos aqui elencados, destacando-se os aspectos de ajudar as pessoas, obter maior autoconhecimento e resolver problemas pessoais. A impossibilidade de alcançar algumas destas expectativas está na base das razões para a evasão, de acordo com os estudos aqui revisados.

Atrelando-se ao exposto, Santos e Melo-Silva (2003) afirmam que há expectativas de papéis profissionais altamente idealizadas também em estudantes de outros cursos superiores, não sendo esta uma característica exclusiva daqueles que optam pelo curso de graduação em psicologia. Uma possível explicação para as expectativas idealizadas pode ser o fato de que muitos indivíduos realizam escolhas de carreira com poucos conhecimentos sobre as implicações das mesmas em termos de tarefas, dificuldades e responsabilidades (Bardagi, Lassance, \& Paradiso, 2003).

Somente em um dos estudos (Palma, 2007) apareceram motivos de escolha relacionados também à instituição de ensino superior em si e da cidade na qual a mesma se localiza. Dado semelhante foi evidenciado na pesquisa de Palharini e Palharini (2008), na qual diplomados do curso de graduação em psicologia afirmaram que a escolha foi baseada, em grande parte, pela instituição de ensino superior em si e pela localização da mesma.

Em todos os estudos analisados, a maior parcela dos evadidos afirmou que o curso de graduação em psicologia constituiu-se como a primeira opção no vestibular. Se, por um lado, pode-se analisar que a tendência é que o estudante permaneça no curso, uma vez que este foi sua primeira opção de escolha, por outro lado, conforme apontam Bardagi e Hutz (2009), a quantidade de informações que os estudantes possuem ao realizar a escolha profissional é, além 
de reduzida, geralmente inconsistente. Assim sendo, a escolha do curso como primeira opção nem sempre refere que o sujeito detém as informações básicas necessárias (e consistentes) sobre o curso em si e sobre a futura carreira e, desse modo, pode haver decepção com a escolha, ocasionando na ocorrência da evasão. Por outro lado, é interessante analisar o dado apresentado pelo estudo de Palma (2007), no qual alguns evadidos declararam sentirem-se satisfeitos em relação ao curso e à vivência acadêmica como um todo. Nesse caso, verifica-se que a satisfação com o curso, embora seja primordial para uma trajetória acadêmica com engajamento, por si só não é responsável por manter o estudante na graduação.

Quanto aos motivos para a evasão dos cursos de graduação em psicologia, os principais motivos elencados pelos estudos aqui encontrados foram: dificuldade financeira; dificuldade para conciliar a vida acadêmica com compromissos familiares e de trabalho; dificuldades pessoais; dúvidas quanto à escolha do curso e à futura atuação profissional, gerando baixa motivação; decepção e insatisfação em relação ao curso e/ou às perspectivas profissionais futuras; baixo comportamento exploratório antes e após o ingresso no curso, gerando falta de informações sobre o curso e a profissão. De modo geral, verifica-se que os motivos de ordem pessoal foram enfatizados como influenciadores da evasão do curso superior.

Para além disso, nos estudos de Castro (2012) e Lima et al. (2015) os evadidos mencionaram, também, motivos institucionais, a saber: relacionamento frio/ distante com professores; focalização do currículo em algumas áreas específicas; conflitos entre visões diferentes da psicologia, gerando divergências entre os departamentos (e mesmo entre os estudantes) e a infraestrutura do campus. Em dois estudos (Alves, 2004; Barone, 2003) apareceram fatores influenciadores da evasão relacionados mais especificamente ao processo de ensino-aprendizagem, sendo eles: dificuldade em acompanhar o curso; nervosismo, ansiedade e dificuldade em obter êxito em relação às avaliações; e dificuldade em produzir texto escrito e elaborar resumo. Ainda, a pesquisa de Palma (2007) indicou motivos de casamento/namoro, mudança de cidade e aprovação em outro vestibular como influenciadores da evasão, sendo que nenhum destes motivos foi mencionado nos demais estudos.

No estudo de Alves (2004) apareceu o fator problemas psicológicos como influenciador da evasão.
Bohry (2007) investigou 40 estudantes que solicitaram trancamento geral de matrícula por motivos de saúde na Universidade de Brasília, e constatou que 57,5\% da amostra descreveu como justificativa da solicitação de trancamento de curso algum transtorno mental ou psicossomático. Deve-se considerar que a crise psicológica do estudante em trancamento geral de matrícula é um fator preocupante, uma vez que é maior o risco do mesmo abandonar o curso superior (Bohry, 2007).

Por meio do que se pode analisar tendo em vista alguns dos fatores elencados nas pesquisas supracitadas, como a idealização da profissão, a falta de informação profissional e o baixo comportamento exploratório, percebe-se que estes se constituem como motivos relevantes que podem levar o estudante a evadir-se do curso superior. Especificamente no caso dos cursos de graduação em psicologia não se pode desconsiderar o aspecto de que a escolha por esta profissão está, ainda, atrelada a uma diversidade de crenças acerca de características que são comumente associadas à figura do psicólogo (como o desejo de ajudar as pessoas, a "vocação para conselheiro", e os "poderes do psicólogo"), e que o estudante, por conseguinte, identifica-as em si próprio e considera-se, portanto, "encaixado" na profissão pelo fato de apresentar características como ser calmo, paciente, tranquilo, saber ouvir, aconselhar e mediar (Magalhães, Straliotto, Keller, \& Gomes, 2001). Sendo assim, quando o estudante se depara com a realidade do curso universitário e esta se apresenta diferentemente do que ele havia imaginado, pode ocorrer a decepção, que gera insatisfação com o curso e, em muitas vezes, causa a evasão.

Essa multiplicidade de razões já havia sido apontada por diversos autores que estudam evasão em diferentes contextos, como Cislaghi (2008). Desse modo, é evidente que estratégias de enfrentamento à evasão precisam contemplar essa diversidade, tanto no campo da psicologia quanto em outras áreas. Há questões que são gerais, como as dificuldades de conciliar trabalho e estudo, por exemplo, mas também, e por isso estudos em contextos de formação específicos são importantes, há razões próprias do ambiente de formação em psicologia, como a busca pelo curso como estratégia de ajuda a si mesmo.

No que tange às possíveis ações a ser realizadas visando reduzir a evasão nos cursos de graduação em psicologia, os estudos analisados enfatizaram, de modo geral, aspectos que se complementam. 
Dentre os aspectos citados, pode-se destacar a necessidade da revisão dos currículos, maior integração entre professores e estudantes, o estreitamento da distância entre estudante e instituição (propiciando a familiaridade do estudante com o contexto acadêmico e as possibilidades do desenvolvimento do mesmo neste nível de ensino), além da necessidade de as IES melhorarem o manejo de casos de evasão.

Nesse sentido, pensando nas estratégias que as próprias instituições de ensino superior podem desenvolver para buscar reduzir os casos de evasão (tanto de modo geral, quanto em cursos específicos), Tontini e Walter (2014) apontam que diversas ações operacionais, pedagógicas, administrativas e de serviços das próprias IES podem contribuir significativamente para a redução dos níveis de evasão, uma vez que além de diagnosticar a propensão à evasão é importante que estratégias sejam empregadas para a retenção dos estudantes. Deve-se considerar tanto aspectos individuais de cada estudante (como a identificação do mesmo com o curso, as possíveis dificuldades para acompanhar as aulas, entre outros fatores) quanto aspectos do próprio curso em si (qualidade do mesmo, qualidade do corpo docente, modo como o currículo está estruturado, entre outros fatores), haja vista que o conjunto desses aspectos pode em muito contribuir para a decisão dos estudantes em evadir-se ou não do curso superior.

De modo geral, os dados aqui analisados apresentam o cenário de pesquisas sobre evasão nos cursos de graduação em psicologia no Brasil. A escassez verificada confirma a pouca atenção concedida aos estudos sobre evasão no contexto específico do curso superior em questão, o que embora possa ser analisado pelo fato desse curso não figurar entre aqueles com índices tradicionalmente elevados de evasão (como as licenciaturas), não significa que sua importância deveria ser reduzida. Espera-se que os dados e as considerações apresentadas auxiliem os pesquisadores e práticos que se dedicam às questões do ensino superior e, também, àqueles que se dedicam à formação de estudantes nos cursos de graduação em psicologia, uma vez que, por meio do conhecimento dos principais motivos elencados por evadidos deste curso como influenciadores do abandono, pode-se planejar e implantar estratégias de prevenção ao fenômeno da evasão.

\section{Referências}

Almeida, L. S., \& Soares, A. P. (2003). Os estudantes universitários: sucesso escolar e desenvolvimento psicossocial. In E. Mercuri \& S. A. J. Polydoro (Orgs.), Estudante universitário: Características e experiências de formação (pp. 15-40). Taubaté, SP: Cabral Editora.

Alves, E. Z. J. (2004). Da formação em Psicologia: O problema da evasão (Um estudo de caso na Universidade Católica de Santos) (Dissertação de Mestrado). Universidade Católica de Santos, Santos, SP.

Andriola, W. B., Andriola, C. G., \& Moura, C. P. (2006). Opiniões de docentes e de coordenadores acerca do fenômeno da evasão discente dos cursos de graduação da Universidade Federal do Ceará (UFC). Ensaio: Avaliação e Políticas Públicas em Educação, 14(52), 365-382.

Arce, M. E., Crespo, B., \& Míguez-Álvarez, C. (2015). Higher education drop-out in Spain: Particular case of universities in Galicia. International Education Studies, 8(5), 247-264.

Bardagi, M. P. (2007). Evasão e comportamento vocacional de universitários: estudos sobre o desenvolvimento de carreira na graduação (Tese de Doutorado). Universidade Federal do Rio Grande do Sul, Porto Alegre, RS.

Bardagi, M. P., \& Hutz, C. S. (2009). “Não havia outra saída”: percepções de alunos evadidos sobre o abandono do curso superior. Psico-USF, 14(1), 95-105.

Bardagi, M. P., Lassance, M. C. P., \& Paradiso, A. C. (2003). Trajetória acadêmica e satisfação com a escolha profissional de universitários em meio de curso. Revista Brasileira de Orientação Profissional, 4(1-2), 153-166.

Barefoot, B. O. (2004). Higher education's revolving door: confronting the problem of student drop out in US colleges and universities. Open Learning, 19(1), 9-18.

Barone, I. C. (2003). A formação do psicólogo na cidade de São Paulo: A escolha e o abandono do curso (Dissertação de Mestrado). Universidade São Marcos, São Paulo, SP.

Bettoi, W., \& Simão, L. M. (2002). Entrevistas com profissionais como atividade de ensino-aprendizagem desejável na formação do psicólogo. Psicologia: Reflexão e Crítica, 15(3), 613-624, 2002. 
Bohry, S. (2007). Crise psicológica do universitário e trancamento geral de matrícula por motivo de saúde (Dissertação de Mestrado). Universidade de Brasília, Brasília, DF.

Bomfim, E. M. (1994). Psicologia social, psicologia do esporte e psicologia jurídica. In Conselho Federal de Psicologia (Org.), Psicólogo brasileiro: Práticas emergentes e desafios para a formação (pp. 201-243). São Paulo, SP: Casa do Psicólogo.

Bueno, J. M. H., Lemos, C. G., \& Tomé, F. A. M. F. (2004). Interesses profissionais de um grupo de estudantes de Psicologia e suas relações com inteligência e personalidade. Psicologia em Estudo, 9(2), 271-278.

Campos, H. R., \& Jucá, M. R. B. L. (2010). O psicólogo na escola: avaliação da formação à luz das demandas do mercado. In S. F. C. Almeida (Org.), Psicologia escolar: Ética e competências na formação e atuação profissional (3a ed., pp. 37-56). Campinas, SP: Alínea.

Castro, A. K. S. S. (2012). Evasão no ensino superior: um estudo no curso de Psicologia da UFRGS (Dissertação de Mestrado). Universidade Federal do Rio Grande do Sul, Porto Alegre, RS.

Castro, A. K. S. S., \& Teixeira, M. A. P. (2013). A evasão em um curso de Psicologia: Uma análise qualitativa. Psicologia em Estudo, 18(2), 199-209.

Castro, A. K. S. S., \& Teixeira, M. A. P. (2014). Evasão universitária: Modelos teóricos internacionais e o panorama das pesquisas no Brasil. Psicologia Argumento, 32(79), 9-17.

Cislaghi, R. (2008). Um modelo de sistema de gestão do conhecimento em um framework para a promoção da permanência discente no ensino de graduação (Tese de Doutorado). Universidade Federal de Santa Catarina, Florianópolis, SC.

Comissão Especial de Estudos sobre Evasão. (1996). Diplomação, retenção e evasão nos cursos de graduação em instituições de ensino superior públicas. Avaliação, 1(2), 55-65. http://periodicos.uniso.br/ojs/index.php?journal $=$ avaliacao\&page $=$ article $\&$ op $=$ view $\&$ path $\% 5 B \% 5 \mathrm{D}=739 \&$ path $\% 5 \mathrm{~B} \% 5 \mathrm{D}=751$

Cruces, A. V. V., \& Maluf, M. R. (2007). Psicólogos recém-formados: Oportunidades de trabalho e atuação na área educacional. In H. R. Campos (Org.), Formação em psicologia escolar: Realidades e perspectivas (pp. 163-210). Campinas, SP: Alínea.

Demetriou, C., \& Schmitz-Sciborski, A. (2011). Integration, motivation, strengths and optimism: Retention theories past, present and future. In R. Hayes (Ed.), Proceedings of the 7th National Symposium on Student Retention, Charleston (pp. 300-312). Norman, OK: The University of Oklahoma.

Dias, C. A. (2001) Considerações sobre elaboração de currículos para formação de psicólogos: a partir de uma perspectiva didática. Psicologia: Ciência e Profissão, 21(3), 36-49.

Dimenstein, M. D. B. (1998). O psicólogo nas Unidades Básicas de Saúde: desafios para a formação e atuação profissional. Estudos de Psicologia, 3(1), 53-81.

Diogo, M. F., Raymundo, L. S., Wilhelm, F. A., Andrade, S. P. C., Lorenzo, F. M., Rost, F. T., \& Bardagi, M. P. (2016). Percepções de coordenadores de curso superior sobre evasão, reprovações e estratégias preventivas. Avaliação, 21(1), 125-151.

Ferreira Neto, J. L. (2004). A formação do psicólogo: clínica, social e mercado. São Paulo, SP: Escuta.

Gomes, W. B. (1996). Pesquisa e ensino em Psicologia: Articulações possíveis entre graduação e pós-graduação. In: R. M. L. L. Carvalho (Org.), Repensando a formação do psicólogo: da informação à descoberta (pp. 33-50). Campinas, SP: Alínea.

Gondim, S. M. G., Magalhães, M. O., \& Bastos, A. V. B. (2010). Escolha da profissão: As explicações construídas pelos psicólogos brasileiros. In A. V. B. Bastos \& S. M. G. Gondim (Orgs.), O trabalho do psicólogo no Brasil (pp. 66-84). Porto Alegre, RS: Artmed.

Heublein, U. (2014). Student drop-out from German higher education institutions. European Journal of Education, 49(4), 497-513.

Hotza, M. P. S. (2000). O abandono nos cursos de graduação da UFSC em 1997: A percepção dos alunos-abandono. (Dissertação de Mestrado). Universidade Federal de Santa Catarina, Florianópolis, SC.

Instituto Nacional de Estudos e Pesquisas Educacionais Anísio Teixeira. (2017a). Sinopse Estatística do Enade 2015. Brasília, DF: Ministério da Educação.

Instituto Nacional de Estudos e Pesquisas Educacionais Anísio Teixeira. (2017b). Censo da Educação Superior 2016: Principais resultados. Brasília, DF: Ministério da Educação. 
Krawulski, E., \& Patrício, Z. M. (2005). Por que pessoas escolhem a Psicologia como profissão? In M. C. P. Lassance et al. (Orgs.), Intervenção e compromisso social. Orientação profissional: teoria e técnica (Vol. 2, pp. 323-336). São Paulo, SP: Vetor.

Lassibille, G., \& Goméz, L. N. (2008). Why do higher education students drop out? Evidence from Spain. Education Economics, 16(1), 89-105.

Lima, M., Coutinho, D., \& Santos, V. (2015). Trajetórias interrompidas no curso de Psicologia em relação ao Bacharelado Interdisciplinar na UFBA. CAMINE: Caminhos da Educação, 7(2), 30-51.

Lins, L. F. T., Silva, L. G., \& Assis, C. L. (2015). Formação em Psicologia: Perfil e expectativas de concluintes do interior do estado de Rondônia. Gerais: Revista Interinstitucional de Psicologia, 8(1), 49-62.

Lisboa, F. S., \& Barbosa, A. J. G. (2009). Formação em Psicologia no Brasil: Um perfil dos cursos de graduação. Psicologia: Ciência e Profissão, 29(4), 718-737.

Magalhães, M., Straliotto, M., Keller, M., \& Gomes, W. B. (2001). Eu quero ajudar as pessoas: A escolha vocacional da psicologia. Psicologia: Ciência e Profissão, 21(2), 10-27.

Maluf, M. R. (1994). Formação e atuação do psicólogo na educação: Dinâmica da transformação. In Conselho Federal de Psicologia (Org.), Psicólogo brasileiro: Práticas emergentes e desafios para a formação (pp. 157-200). São Paulo, SP: Casa do Psicólogo.

Mancebo, D., Vale, A. A., \& Martins, T. B. (2015). Políticas de expansão da educação superior no Brasil 1995-2010. Revista Brasileira de Educação, 20(60), 31-50.

Matos, M. A. (2000). A definição de diretrizes em uma estruturação curricular em Psicologia e o estágio de formação profissional. Psicólogo InFormação, 4(4), 11-24.

Medeiros, J. G. (1989). O currículo como objeto de pesquisa. Psicologia: Ciência e Profissão, 9(1), 16-18.

Mello, S. L. (1983). Psicologia e profissão em São Paulo. São Paulo, SP: Ática.

Nascimento, E. C., Guimarães, J. L., Silva, N. P., \& Bendassolli, P. F. (1999). A evasão escolar no curso de graduação em Psicologia da Unesp de Assis: algumas considerações. Vertentes, 5, 39-47.

Natário, E. G. (1999). A pesquisa na formação do psicólogo. In C. Witter (Org.), Ensino de Psicologia (pp. 25-40). Campinas, SP: Alínea.

Neves, M. M. B. J. (2007). Formação inicial em psicologia escolar: questões apontadas por alunos de graduação. In: H. R. Campos (Org.), Formação em psicologia escolar: Realidades e perspectivas (pp. 49-67). Campinas, SP: Alínea.

Noronha, A. P. P. (2003). Docentes de psicologia: Formação profissional. Estudos de Psicologia, 8(1), 169-173.

Palharini, F. A., \& Palharini, D. B. (2008). Opinião de diplomados sobre o curso de Psicologia da UFF. Fractal: Revista de Psicologia, 20(2), 583-600.

Palma, S. P. V. (2007). Experiências de evasão de um curso de Psicologia (Dissertação de Mestrado). Universidade de São Paulo, Ribeirão Preto, SP.

Pfromm Netto, S. (2007). Psicologia, psicologias: Velhos e novos olhares. Algumas considerações sobre o passado, o presente e o futuro da psicologia como ciência, profissão e ensino. Psicologia em Pesquisa, 1(1), 8-13.

Polydoro, S. A. J. (2000). O trancamento de matrícula na trajetória acadêmica do universitário: Condições de saída e de retorno à instituição (Tese de Doutorado). Universidade Estadual de Campinas, Campinas, SP.

Prim, A. L., \& Fávero, J. D. (2013). Motivos da evasão escolar nos cursos de ensino superior de uma faculdade na cidade de Blumenau. Revista E-Tech, 3(n. esp.), 53-72.

Ribeiro, M. A. (2005). O projeto profissional familiar como determinante da evasão universitária: um estudo preliminar. Revista Brasileira de Orientação Profissional, 6(2), 55-70.

Ristoff, D. I. (1995). Evasão: exclusão ou mobilidade. Florianópolis, SC: UFSC.

Ristoff, D. I. (1999). Universidade em Foco: Reflexões sobre a educação superior. Florianópolis, SC: Insular.

Robbins, S. B., Lauver, K., Le, H., Davis, D., Langley, R., \& Carlstrom, A. (2004). Do psychosocial and study skill factors predict college outcomes? A meta-analysis. Psychological Bulletin, 130(2), 261-288. 
Santos, M. A., \& Melo-Silva, L. L. (2003). “Será que era isso o que eu queria?”: A formação acadêmica em Psicologia na perspectiva do aluno. In L. L. Melo-Silva et al. (Orgs.), Arquitetura de uma ocupação. Orientação profissional: Teoria e técnica (Vol. 1, pp. 387-406). São Paulo, SP:Vetor.

Saviani, D. (2010). A expansão do ensino superior no Brasil: Mudanças e continuidades. Poíesis Pedagógica, 8(2), 4-17.

Silva, N. P. (1994). Entre o ideal e o real: Um estudo sobre as razões que levam alunos de uma universidade pública à intenção de abandonar o curso de Psicologia (Dissertação de Mestrado). Pontifícia Universidade Católica de São Paulo, São Paulo, SP.

Silva, S. M. C. (2004). Algumas reflexões sobre a arte e a formação do psicólogo. Psicologia: Ciência e Profissão, 24(4), 100-111.

Silva Filho, R. L. L., Motejunas, P. R., Hipólito, O., \& Lobo, M. B. C. M. (2007). A evasão no ensino superior brasileiro. Cadernos de Pesquisa, 37(132), 641-659.

Sindicato das Entidades Mantenedoras de Estabelecimentos de Ensino Superior no Estado de São Paulo. (2016). Mapa do Ensino Superior no Brasil 2016. São Paulo, SP: Semesp.

Souza, M. P. R. (2007). Reflexões a respeito da atuação do psicólogo no campo da psicologia escolar/educacional em uma perspectiva crítica. In H. R. Campos (Org.), Formação em psicologia escolar: Realidades e perspectivas (pp. 149-162). Campinas, SP: Alínea.

Tontini, G., \& Walter, S. A. (2014). Pode-se identificar a propensão e reduzir a evasão de alunos? Ações estratégicas e resultados táticos para instituições de ensino superior. Avaliação, 19(1), 89-110.

Witter, G. P., \& Ferreira, A. A. (2005). Formação do psicólogo hoje. In Conselho Federal de Psicologia (Org.), Psicólogo brasileiro: Construção de novos espaços (pp. 15-39). Campinas, SP: Alínea.

Yamamoto, O. H. (2006). Graduação e pós-graduação em psicologia: Relações possíveis. Revista Brasileira de Pós-Graduação, 3(6), 270-281.

Zanelli, J. C. (1994). Movimentos emergentes na prática dos psicólogos brasileiros nas organizações de trabalho: Implicações para a formação. In Conselho Federal de Psicologia (Org.), Psicólogo brasileiro: Práticas emergentes e desafios para a formação (pp. 81-156). São Paulo, SP: Casa do Psicólogo.

\section{Carlos Alexandre Campos}

Psicólogo. Mestre em Psicologia pela Universidade Federal de Santa Catarina. Doutorando em Psicologia pela Universidade Federal de Santa Catarina, Florianópolis - SC. Brasil.

E-mail: carloscampos_psico@yahoo.com.br

(D) https://orcid.org/0000-0002-9419-0567

\section{Marucia Patta Bardagi}

Psicóloga. Doutora em Psicologia pela Universidade Federal do Rio Grande do Sul. Docente do Curso de Graduação em Psicologia e do Programa de Pós-Graduação em Psicologia da Universidade Federal de Santa Catarina, Florianópolis - SC. Brasil.

E-mail: marucia.patta@ufsc.br

(D) https://orcid.org/0000-0003-0224-2794

Endereço para envio de correspondência:

Universidade Federal de Santa Catarina. Rua Engenheiro Agronômico Andrei Cristian Ferreira, s/n, CFH, Bloco C, Depto. Psicologia, Sala 14B. Trindade. CEP: 88040-900. Florianópolis - SC. Brasil.

Recebido $18 / 08 / 2018$

Aceito 22/04/2019

Received 18/08/2018

Approved 22/04/2019

Recibido 18/08/2018

Aceptado 22/04/2019 
Como citar: Campos, C. A., \& Bardagi, M. P. (2020). A Evasão nos Cursos de Psicologia no Brasil: Uma Revisão da Literatura. Psicologia: Ciência e Profissão, 40, 1-17.

https://doi.org/10.1590/1982-3703003212214

How to cite: Campos, C. A., \& Bardagi, M. P. (2020). The Dropout in Psychology Courses in Brazil: a Literature Review. Psicologia: Ciência e Profissão, 40, 1-17.

https://doi.org/10.1590/1982-3703003212214

Cómo citar: Campos, C. A., \& Bardagi, M. P. (2020). La Evasión en los Cursos de Psicología en Brasil: Una Revisión de la Literatura. Psicologia: Ciência e Profissão, 40, 1-17.

https://doi.org/10.1590/1982-3703003212214 